\title{
BMI-1, a promising therapeutic target for human cancer (Review)
}

\author{
MIN-CONG WANG, CHUN-LI LI, JIE CUI, MIN JIAO, TAO WU, LI JING and KE-JUN NAN \\ Department of Oncology, The First Affiliated Hospital, \\ College of Medicine of Xi'an Jiaotong University, Xi'an, Shaanxi 710061, P.R. China
}

Received July 1, 2014; Accepted March 12, 2015

DOI: $10.3892 / \mathrm{ol} .2015 .3361$

\begin{abstract}
BMI-1 oncogene is a member of the polycomb-group gene family and a transcriptional repressor. Overexpression of BMI-1 has been identified in various human cancer tissues and is known to be involved in cancer cell proliferation, cell invasion, distant metastasis, chemosensitivity and patient survival. Accumulating evidence has revealed that BMI-1 is also involved in the regulation of self-renewal, differentiation and tumor initiation of cancer stem cells (CSCs). However, the molecular mechanisms underlying these biological processes remain unclear. The present review summarized the function of BMI-1 in different human cancer types and CSCs, and discussed the signaling pathways in which BMI-1 is potentially involved. In conclusion, BMI-1 may represent a promising target for the prevention and therapy of various cancer types.
\end{abstract}

\section{Contents}

1. Introduction

2. BMI-1 and human cancer

3. Association between BMI-1 and CSCs

4. Signaling pathways of BMI-1 in the regulation of cancer and CSCs

5. Conclusions

Correspondence to: Professor Ke-Jun Nan, Department of Oncology, The First Affiliated Hospital, College of Medicine of Xi'an Jiaotong University, 277 Yanta West Road, Xi'an, Shaanxi 710061, P.R. China

E-mail:nankj@163.com

Abbreviations: CSCs, cancer stem cells; $\mathrm{PcG}$, polycomb group

Key words: therapeutic target, BMI-1, human cancer, cancer stem cells, poor prognosis

\section{Introduction}

At present, the success of cancer treatment is challenging and one of the key determinants of treatment failure may be the presence of cancer stem cells (CSCs) (1). This small proportion of tumor cells plays a pivotal role in tumor growth, proliferation, invasion, distant metastasis and relapse of numerous types of cancer (2). Therefore, identifying a reliable biomarker that is associated with the treatment of human cancer and CSCs is important.

The role of oncogenic BMI-1 (also known as B-lymphoma Moloney murine leukemia virus insertion region-1), a member of the polycomb-group ( $\mathrm{PcG}$ ) family of proteins, in cancer has attracted increasing attention. Biehs et al have demonstrated that BMI-1 was important in the maintenance of stem cell properties in a mouse incisor model (3). Certain studies have also revealed that BMI-1 was involved in the self-renewal, differentiation and tumor initiation of CSCs (3-5). In addition, BMI-1 is known to be upregulated in various human cancer tissues and is important in the regulation of malignant transformation, proliferation, cell cycle, apoptosis and distant metastasis (6). The present review summarized the role of BMI-1 in human cancer and CSCs, and discussed the signaling pathways in which BMI-1 is involved. Furthermore, the potential of BMI-1 as a critical prognostic marker, as well as a future therapeutic target, was reviewed.

\section{BMI-1 and cancer}

BMI-1 was first identified in a B-cell lymphoma as a transcriptional repressor that was a member of the $\mathrm{PcG}$ transcription factors (7). Overexpression of BMI-1 has been previously reported in gastric, ovarian, breast, head and neck, pancreatic and lung cancer, as well as in primary hepatocellular carcinoma (HCC) and endometrial carcinoma (8-16). In addition, BMI-1 overexpression has been identified in patients suffering from myelodysplastic syndrome, chronic myeloid leukemia, acute myeloid leukemia and lymphoma (17-20). Previous studies have indicated that the increased BMI-1 expression was associated with tumor proliferation, invasion/metastasis, chemosensitivity and patient survival (Table I).

Numerous studies have indicated that BMI-1 may promote tumor cell growth (Table I). The overexpression of BMI-1 in gastric and breast cancer has been identified to promote cell growth and proliferation, inhibit apoptosis and 
Table I. Effects of BMI-1 expression in different tumor types.

\begin{tabular}{|c|c|c|c|c|c|c|c|c|}
\hline \multirow[b]{2}{*}{ Tumor type } & \multicolumn{3}{|c|}{ In vitro } & \multirow[b]{2}{*}{ Refs } & \multicolumn{3}{|c|}{ In vivo (patients) } & \multirow[b]{2}{*}{ Refs } \\
\hline & $\begin{array}{c}\text { Cell } \\
\text { proliferation }\end{array}$ & $\begin{array}{c}\text { Cell } \\
\text { invasion }\end{array}$ & Chemosensitivity & & $\begin{array}{c}\text { Tumor } \\
\text { metastasis }\end{array}$ & $\begin{array}{l}\text { Patient } \\
\text { survival }\end{array}$ & $\begin{array}{l}\text { Drug } \\
\text { resistance }\end{array}$ & \\
\hline Gastric cancer & $(+)$ & $(+)$ & ND & $(6,7)$ & $(+)$ & ND & $(+)$ & $(16,17)$ \\
\hline Hepatocellular carcinoma & ND & $(+)$ & $(+)$ & $(13,30)$ & $(+)$ & ND & ND & (13) \\
\hline Pancreatic cancer & $(+)$ & $(+)$ & $(+)$ & $(8-11)$ & $(+)$ & $(+)$ & ND & (8) \\
\hline Lung cancer & $(+)$ & ND & ND & (12) & $(+)$ & $(+)$ & ND & $(18-20)$ \\
\hline Endometrial carcinomas & ND & $(+)$ & ND & (15) & $(+)$ & ND & ND & (22) \\
\hline Ovarian cancer & ND & ND & $(+)$ & $(31,32)$ & $(+)$ & $(+)$ & ND & $(4,40)$ \\
\hline Breast cancer & $(+)$ & ND & ND & (4) & $(+)$ & ND & $(+)$ & $(26-29,38,39)$ \\
\hline Head and neck cancer & ND & $(+)$ & ND & (14) & $(+)$ & $(+)$ & ND & $(23-25)$ \\
\hline Hematological malignancy & ND & ND & $(+)$ & (37) & $(+)$ & $(+)$ & $(+)$ & $(33-36)$ \\
\hline
\end{tabular}

Refs, references; ND, no data available; (+), positive correlation.

enhanced clone formation capability $(6,21,22)$. By contrast, the depletion of BMI-1 in certain pancreatic cancer cell lines was found to suppress cell proliferation, sensitize apoptosis and inhibit tumor formation in nude mice $(13,23-25)$. In addition, upregulation of BMI-1 expression enhanced the ability of colony formation in a soft agar assay in non-small cell lung cancer (NSCLC) tissues (26).

Invasion/metastasis of cancer is commonly associated with poor prognosis in patients. Strong evidence supports the involvement of BMI-1 in tumor cell invasion in gastric cancer, primary HCC, pancreatic cancer, endometrial carcinoma, and head and neck cancer (Table I). Overexpression of BMI-1 in gastric cancer resulted in increased migration and invasion abilities $(21,22)$, while BMI-1 depletion reduced the invasiveness of HCC cells (15). Song et al also identified that upregulation of BMI-1 expression enhanced the motility and invasiveness of human nasopharyngeal epithelial cells, whereas silencing of BMI-1 expression reduced motility (27). Epithelial-mesenchymal transition (EMT) is the key process driving cancer metastasis and BMI-1 has been demonstrated to induce EMT in endometrial carcinoma cells (28). Furthermore, in vivo studies revealed that BMI-1 expression was upregulated in cancer tissues compared with matched healthy tissues and was associated with distant metastases of gastric cancer $(8,29), \operatorname{HCC}(15)$, lung cancer $(14,30,31)$, endometrial carcinomas $(16,28,32)$, and head and neck cancer $(11,12,33)$. Several previous studies have also suggested that BMI-1 contributed to mammary carcinogenesis, axillary lymph node metastases, highly aggressive behavior and late-stage relapse in breast cancer $(6,10,34-36)$.

Drug resistance is an important cause of cancer treatment failure and previous studies have demonstrated that the overexpression of BMI-1 was associated with cancer chemosensitivity (Table I) $(9,30,31)$. Certain in vitro studies revealed that overexpression of BMI-1 can promote chemoresistance (23), whereas depletion of BMI-1 is able to enhance the chemosensitivity of HCC $(15,37)$ and ovarian cancer cells $(38,39)$. In a clinical setting, the overexpression of BMI-1 may facilitate drug resistance in hematological malignancies, including the myelodysplastic syndrome, chronic myeloid leukemia, acute myeloid leukemia and lymphoma (17-20,40). In addition, BMI-1 has been demonstrated to play an important role in chemoresistance and radiosensitivity in breast cancer $(41,42)$.

BMI-1 has also been found to be associated with the survival of pancreatic cancer, NSCLC, ovarian carcinoma, head and neck cancer, and hematological malignancy patients (Table I), suggesting that BMI-1 is a significant prognostic factor of poor survival. For instance, Song et al investigated the survival of 72 patients with pancreatic cancer and identified that the overexpression of BMI-1 was associated with a significantly reduced overall survival (24). In addition, Yang et al studied the BMI-1 expression and survival in a cohort of 179 patients with invasive ovarian carcinoma (9). The authors demonstrated a significant association between increased BMI-1 expression and reduced patient survival (mean, 49 months), when compared with patients presenting a low BMI-1 expression (mean, 100 months; P<0.001) (9). Furthermore, Vrzalikova et al performed immunohistochemical staining for BMI-1 in 179 NSCLC samples, identifying that the five-year survival rate of BMI-1-positive patients was only $31.2 \%$, in contrast to BMI-1-negative patients that exhibited a survival rate of $50.7 \%(\mathrm{P}=0.004)(43)$.

Overexpression of BMI-1 has also been revealed to correlate with pediatric brain tumors, skin cancer, melanoma, prostate cancer and bladder cancer (44-47). Cancer cell proliferation, invasion/metastasis and chemosensitivity are associated with cancer treatment failure and may induce poor prognosis in patients. However, numerous studies have demonstrated that the treatment failure of various human cancer types is associated with CSCs $(3,48)$. BMI-1 has received increasing attention, since it has been demonstrated to be important in maintaining the properties of CSCs. Therefore, studies further addressing the effect of BMI-1 on CSCs are essential to understand the role of CSCs in human cancer, and may lead to improved treatment strategies. 


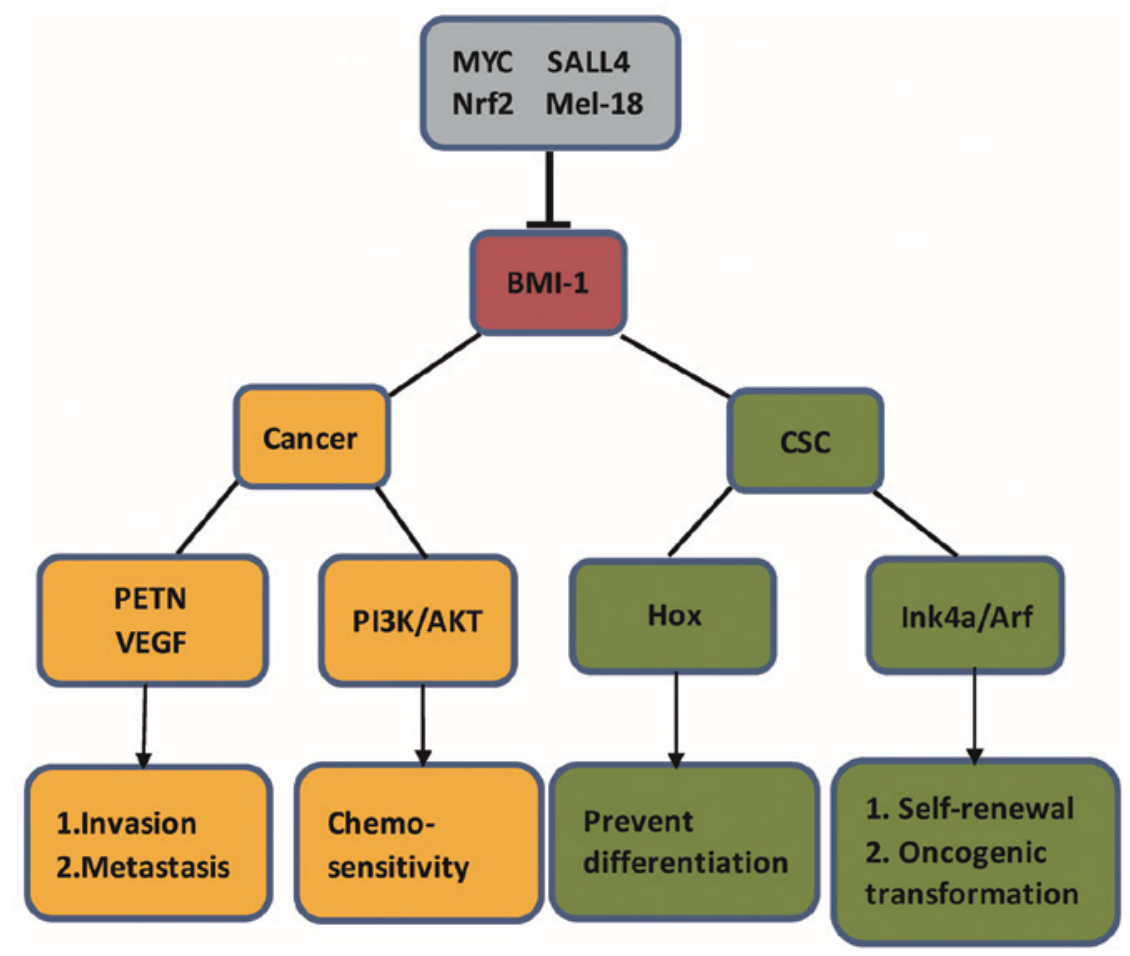

Figure 1. BMI-1 is important in the regulation of cancer and CSCs, functioning through the activation of multiple signaling pathways. BMI-1 expression is upregulated by MYC, SALL4, Nrf2 and is downregulated by Mel-18. BMI-1 regulates cancer cell invasion/metastasis and chemosensitivity by regulating VEGF, PTEN and PI3K/AKT signaling pathway. BMI-1 regulates CSC differentiation through repression of Hox genes, regulates self-renewal and malignant transformation through repression of Ink4a/Arf genes. CSC, cancer stem cell; VEGF, vascular endothelial growth factor. Nrf2, nuclear factor erythroid 2-related factor 2.

\section{Association between BMI-1 and CSCs}

The CSC hypothesis was first described by Park et al (49) in 1971. Advances in CSC isolation were initially achieved in hematological malignancies, with CSCs first detected in acute myeloid leukemia. Subsequently, using similar strategies and technologies, and taking advantage of available surface markers, CSCs have been identified in a range of epithelial and other solid organ malignancies, indicating that these cells are involved in the majority of malignancies (50). CSCs are defined by their extensive self-renewal, differentiation and tumor initiation properties (3-5). Thus, the signaling pathways required for the maintenance of CSCs are candidate targets for a successful molecular therapy of various tumors. Recent studies have demonstrated that BMI-1 is involved in the regulation of CSCs.

BMI-1 is indispensable for the regulation of self-renewal by normal stem cells, leukemic stem cells (LSCs) and hematopoietic stem cells (HSCs) (51-54). For instance, Park et al (54) revealed that the number of HSCs in the fetal liver of $B M I-1$-null mice was normal, whereas it was markedly reduced in postnatal $B M I-1$-null mice. In addition, transplanted fetal liver and bone marrow cells obtained from the mice were able to contribute only transiently to hematopoiesis. No self-renewal was detected in adult HSCs, indicating a cell autonomous defect in BMI-1-null mice (54) and the importance of BMI-1 in the self-renewal of normal stem cells.

BMI-1 is also indispensable for the regulation of self-renewal in human solid tumors, including oral, esophageal, prostate, pancreatic, neuronal, non-small cell lung and breast cancer $(2,26,48,55-58)$. In order to examine the function of BMI-1 in stem cells, Lukacs et al identified that decreased expression of BMI-1 in prostate cells reduced the number and size of spheres formed by these cells, while increased BMI-1 expression enhanced the sphere formation and size (4). Furthermore, Biehs et al reported that BMI-1 was expressed by incisor stem cells and that deletion of BMI-1 resulted in a reduced number of stem cells and perturbed gene expression (3). BMI-1 is known to be highly enriched in CD133-positive cells of human glioblastoma multiforme (GBM). A previous cell biology study revealed that BMI-1 prevents CD133-positive cell apoptosis and differentiation into neurons and astrocytes (5). In addition, the study demonstrated that BMI-1 is involved in GBM tumor growth and required to sustain CSC renewal and differentiation (5).

CSCs are associated with tumor initiation and malignant transformation. Previous studies demonstrated that BMI-1 plays an important role in these processes. For instance, in breast cancer, CSCs were no longer able to initiate tumors following the knocking down of BMI-1 expression by short hairpin RNA (59). However, tumor initiation was rescued with the introduction of a BMI-1 overexpression vector in the BMI-1 knockdown cells (59). In a clinical setting, a high expression of BMI-1 is associated with precancerous lesions of esophageal adenocarcinoma (60) and oral cancer (61), which implies that BMI-1 is involved in malignant transformation.

Considering the aforementioned findings, BMI-1 is required for the maintenance of self-renewal, tumor initiation and prevention of inappropriate differentiation of CSCs. However, the molecular mechanisms underlying these biological processes remain unclear. 


\section{Signaling pathways of BMI-1 in the regulation of cancer and CSCs}

Upstream signaling pathways. Notably, previous studies have implicated MYC in the regulation of the chromatin structure, which is reprogrammed in stem cells. MYC is able to modulate BMI-1 by adjusting the expression of the microRNA, miR-9, and long non-coding RNAs that are involved in polycomb-mediated gene silencing $(27,62-65)$. Coskun et al (66) and Ke et al (67) demonstrated that the bFGF-SHP2-ERK-c-MYC-BMI-1 signaling pathway is critical for the self-renewal capacity of neural stem cells.

$S A L L 4$, a member of the SALL gene family, is one of the most important transcriptional regulators of stem cells. This gene is of particular interest to stem cell biologists, due to its association with the self-renewal of embryonic stem cells and HSCs. In normal HSCs and LSCs, SALL4 is linked to $B M I-1$ (68). Yang et al demonstrated that BMI-1 is a direct target gene of SALL4 (69). The induction of SALL4 expression was demonstrated to be associated with increased levels of histone methylation (H3-K4 and H3-K79) in the BMI-1 promoter (69).

Nuclear factor erythroid 2-related factor 2 (Nrf2) is an important nuclear transcription factor, which regulates antioxidant response element-containing genes. Zhu et al revealed that knockdown of Nrf2 inhibited the proliferation of glioma stem cells and significantly reduced the expression levels of BMI-1, Sox2 and cyclin E (70).

Mel-18 is one of the PcG proteins, which function as transcriptional repressors through epigenetic regulation, including histone modifications and DNA methylation, and their role in tumor development is critical. However, Mel-18 is a putative tumor suppressor in various human cancer tissues, unlike the BMI-1 oncogene. Therefore, Mel-18 has been proposed as a novel negative regulator of BMI-1 as it inhibits breast cancer cell proliferation (71).

Downstream signaling pathways. Inactivation of BMI-1 is known to result in impaired stem cell self-renewal. Although the underlying mechanisms remain unclear, an important gene that is silenced by BMI-1 is Ink4a/Arf. This gene encodes the cell-cycle inhibitors, $\mathrm{p} 16^{\text {Ink4a }}$ and $\mathrm{p} 19^{\text {Arf }}(72)$, which regulate the activities of retinoblastoma ( $\mathrm{Rb})$ and $\mathrm{p} 53$, respectively. In addition, $\mathrm{p} 16^{\mathrm{Ink4a}}$ and $\mathrm{p} 19^{\text {Arf }}$ restrain cell proliferation by partly overlapping signaling pathways that control the cell cycle, cell differentiation, senescence and survival $(57,73,74)$. Chiba et al have indicated that repression of Ink4a/Arf is crucial in the oncogenic transformation of hepatic stem cells (75). A number of studies have also demonstrated that BMI-1 is able to promote stem cell self-renewal mainly by interfering with two signaling pathways, p16 $6^{\text {Ink4a }} / \mathrm{Rb}$ and Arf/p53 (20,76,77). Therefore, through the regulation of $\mathrm{p} 16^{\text {Ink4a }}$ and Arf, BMI-1 is involved in the malignant transformation and self-renewal of CSCs.

However, other BMI-1 targets may also exist, since the effects of BMI-1 on stem cells are not fully reversed by the deletion of the Ink4a/Arf gene (3). A previous study proposed a general BMI-1-mediated mechanism for the maintenance of CSCs and the prevention of inappropriate differentiation (3). Other studies have also demonstrated that the Hox gene is upregulated when $B M I-1$ is inactivated $(3,54,78-80)$. In addition, Biehs et al (3) have established that the deletion of Ink4a/Arf is able to only partially rescue BMI-1-null phenotypes and revealed that Hox expression is typically repressed by BMI-1. In addition, the authors demonstrated that the BMI-1-mediated repression of Hox genes preserves the undifferentiated state of stem cells (3).

Using chromatin immunoprecipitation assays, Song et al revealed that BMI-1 transcriptionally downregulated the expression of the tumor suppressor, phosphatase and tensin homolog (PTEN), in tumor cells through direct association with the PTEN locus (27). In addition, the authors observed that ablation of PTEN expression resulted in partial rescue of the migratory/invasive phenotype of BMI-1-silenced cells (27). Furthermore, Li et al established that inhibition of BMI-1 reduced the invasiveness of two HCC cell lines in vitro by upregulating PTEN expression (15). Angiogenesis is an essential process for sustaining tumor invasion and metastasis. A previous study demonstrated that BMI-1 is involved in glioma angiogenesis (81). Vlachostergios and Papandreou have revealed the involvement of the BMI-1/NF-кB/VEGF signaling pathway in the promotion of glioma cell-mediated migration of endothelial cells and neovascularization in vitro and in vivo, while NF- $\kappa \mathrm{B}$ inhibition was demonstrated to reverse these effects (82). These results demonstrated that BMI-1 is involved in the invasiveness of cancer by regulating the expression of PTEN and the vascular endothelial growth factor. Finally, BMI-1 depletion enhances the chemosensitivity of HCC cells by inducing apoptosis and autophagy, which is associated with the PI3K/AKT signaling pathway (Fig. 1) (37).

\section{Conclusions}

A number of previous studies have demonstrated that BMI-1, a member of the PcG family, is associated with various types of human cancer and overexpression of BMI-1 plays a vital role in cancer cell proliferation, invasion/metastasis, chemosensitivity and patient survival. Furthermore, BMI-1 is involved in the maintenance of self-renewal, tumor initiation and prevention of inappropriate differentiation of CSCs by participating in multiple signaling pathways, suggesting that BMI-1 is important in maintaining the CSC properties. The presence of CSCs induces treatment failure of human tumors. Certain studies have indicated that silencing BMI-1 can reduce the malignant biological behavior of cancer, as well as the self-renewal and differentiation of CSCs. Therefore, BMI-1 is hypothesized to affect the malignant biological behavior of human tumors by regulating the self-renewal and differentiation of CSCs. In conclusion, BMI-1 may represent a promising target for the prevention and therapy of various human cancer types. Further understanding the molecular mechanism underlying the regulation of BMI-1 in human cancer and CSCs is of great clinical value.

\section{Acknowledgements}

This study was supported by grants from the National Natural Science Foundation of China (no. 81101523). 


\section{References}

1. Sayed SI, Dwivedi RC, Katna R, et al: Implications of understanding cancer stem cell (CSC) biology in head and neck squamous cell cancer. Oral Oncol 47: 237-243, 2011.

2. Sinha N, Mukhopadhyay S, Das DN, Panda PK and Bhutia SK Relevance of cancer initiating/stem cells in carcinogenesis and therapy resistance in oral cancer. Oral Oncol 49: 854-862, 2013.

3. Biehs B, Hu JK, Strauli NB, et al: BMI1 represses Ink4a/Arf and Hox genes to regulate stem cells in the rodent incisor. Nat Cell Biol 15: 846-852, 2013.

4. Lukacs RU, Memarzadeh S, Wu H and Witte ON: Bmi-1 is a crucial regulator of prostate stem cell self-renewal and malignant transformation. Cell Stem Cell 7: 682-693, 2010.

5. Abdouh M, Facchino S, Chatoo W, Balasingam V, Ferreira J and Bernier G: BMI1 sustains human glioblastoma multiforme stem cell renewal. J Neurosci 29: 8884-8896, 2009.

6. Gavrilescu MM, Todosi AM, Aniţei MG, Filip B and Scripcariu V: Expression of bmi-1 protein in cervical, breast and ovarian cancer. Rev Med Chir Soc Med Nat Iasi 116: 1112-1117, 2012.

7. Alkema MJ, Wiegant J, Raap AK, Berns A and van Lohuizen M: Characterization and chromosomal localization of the human proto-oncogene BMI-1. Hum Mol Genet 2: 1597-1603, 1993.

8. Yang DD, Cui BB, Sun LY, et al: The co-expression of USP22 and BMI-1 may promote cancer progression and predict therapy failure in gastric carcinoma. Cell Biochem Biophys 61: 703-710, 2011.

9. Yang GF, He WP, Cai MY, et al: Intensive expression of Bmi-1 is a new independent predictor of poor outcome in patients with ovarian carcinoma. BMC Cancer 10: 133, 2010.

10. Guo BH, Feng Y, Zhang R, et al: Bmi-1 promotes invasion and metastasis and its elevated expression is correlated with an advanced stage of breast cancer. Mol Cancer 10: 10, 2011

11. Häyry V, Mäkinen LK, Atula T, et al: Bmi-1 expression predicts prognosis in squamous cell carcinoma of the tongue. $\mathrm{Br} \mathrm{J}$ Cancer 102: 892-897, 2010.

12. Song LB, Zeng MS, Liao WT, et al: Bmi-1 is a novel molecular marker of nasopharyngeal carcinoma progression and immortalizes primary human nasopharyngeal epithelial cells. Cancer Res 66: 6225-6232, 2006

13. Chang Z, Li Z, Wang X, et al: Deciphering the mechanisms of tumorigenesis in human pancreatic ductal epithelial cells. Clin Cancer Res 19: 549-559, 2013.

14. Zhang X, Sun J, Wang H, et al: IGF-1R and Bmi-1 expressions in lung adenocarcinoma and their clinicopathologic and prognostic significance. Tumour Biol 35: 739-745, 2014.

15. Li X, Yang Z, Song W, et al: Overexpression of Bmi-1 contributes to the invasion and metastasis of hepatocellular carcinoma by increasing the expression of matrix metalloproteinase (MMP) 2, MMP-9 and vascular endothelial growth factor via the PTEN/PI3K/Akt pathway. Int J Oncol 43: 793-802, 2013.

16. Engelsen IB, Mannelqvist M, Stefansson IM, et al: Low BMI-1 expression is associated with an activated BMI-1-driven signature, vascular invasion and hormone receptor loss in endometrial carcinoma. Br J Cancer 98: 1662-1669, 2008.

17. Molofsky AV, He S, Bydon M, Morrison SJ and Pardal R: Bmi-1 promotes neural stem cell self-renewal and neural development but not mouse growth and survival by repressing the p16Ink4a and p19Arf senescence pathways. Genes Dev 19: 1432-1437, 2005.

18. Mihara K, Chowdhury M, Nakaju N, et al: Bmi-1 is useful as a novel molecular marker for predicting progression of myelodysplastic syndrome and patient prognosis. Blood 107: 305-308, 2006

19. Mohty M, Yong AS, Szydlo RM, Apperley JF and Melo JV: The polycomb group BMI1 gene is a molecular marker for predicting prognosis of chronic myeloid leukemia. Blood 110: 380-383, 2007

20. Abd Al Kader L, Oka T, Takata K, et al: In aggressive variants of non-Hodgkin lymphomas, Ezh2 is strongly expressed and polycomb repressive complex PRC1.4 dominates over PRC1.2. Virchows Arch 463: 697-711, 2013.

21. Chen Y, Lian G, Zhang Q, et al: Overexpression of Bmi-1 induces the malignant transformation of gastric epithelial cells in vitro. Oncol Res 21: 33-41, 2013

22. Gao FL, Li WS, Liu CL and Zhao GQ: Silencing Bmi-1 enhances the senescence and decreases the metastasis of human gastric cancer cells. World J Gastroenterol 19: 8764-8769, 2013.

23. Yin $\mathrm{T}$, Wei $\mathrm{H}$, Leng $\mathrm{Z}$, et al: Bmi-1 promotes the chemoresistance, invasion and tumorigenesis of pancreatic cancer cells Chemotherapy 57: 488-496, 2011.
24. Song W, Tao K, Li H, et al: Bmi-1 is related to proliferation, survival and poor prognosis in pancreatic cancer. Cancer Sci 101: $1754-1760,2010$

25. Guo S, Xu X, Tang Y, et al: miR-15a inhibits cell proliferation and epithelial to mesenchymal transition in pancreatic ductal adenocarcinoma by down-regulating Bmi-1 expression. Cancer Lett 344: 40-46, 2014

26. Kuang BH, Zhang MQ, Xu LH, et al: Proline-rich tyrosine kinase 2 and its phosphorylated form pY881 are novel prognostic markers for non-small-cell lung cancer progression and patients overall survival. Br J Cancer 109: 1252-1263, 2013.

27. Song LB, Li J, Liao WT, et al: The polycomb group protein Bmi-1 represses the tumor suppressor PTEN and induces epithelial-mesenchymal transition in human nasopharyngeal epithelial cells. J Clin Invest 119: 3626-3636, 2009.

28. Dong P, Kaneuchi M, Watari H, et al: MicroRNA-194 inhibits epithelial to mesenchymal transition of endometrial cancer cells by targeting oncogene BMI-1. Mol Cancer 10: 99, 2011.

29. Liu PW, Lin Y and Chen XY: Expression of B-cell-specific Moloney murine leukemia virus integration site $1 \mathrm{mRNA}$ and protein in gastric cancer. J Dig Dis 15: 166-173, 2014.

30. Meng X, Wang Y, Zheng X, et al: shRNA-mediated knockdown of Bmi-1 inhibit lung adenocarcinoma cell migration and metastasis. Lung Cancer 77: 24-30, 2012.

31. Huang J, Qiu Y, Chen G, Huang L and He J: The relationship between Bmi-1 and the epithelial-mesenchymal transition in lung squamous cell carcinoma. Med Oncol 29: 1606-1613, 2012.

32. Colas E, Pedrola N, Devis L, et al: The EMT signaling pathways in endometrial carcinoma. Clin Transl Oncol 14: 715-720, 2012.

33. Huber GF, Albinger-Hegyi A, Soltermann A, et al: Expression patterns of Bmi-1 and p16 significantly correlate with overall disease-specific and recurrence-free survival in oropharyngeal squamous cell carcinoma. Cancer 117: 4659-4670, 2011.

34. Dimri GP, Martinez JL, Jacobs JJ, et al: The Bmi-1 oncogene induces telomerase activity and immortalizes human mammary epithelial cells. Cancer Res 62: 4736-4745, 2002.

35. Wang Y, Zhe H, Ding Z, Gao P, Zhang N and Li G: Cancer stem cell marker Bmi-1 expression is associated with basal-like phenotype and poor survival in breast cancer. World J Surg 36: 1189-1194, 2012.

36. Joensuu K, Hagstrom J, Leidenius M, et al: Bmi-1, c-myc and Snail expression in primary breast cancers and their metastases - elevated Bmi-1 expression in late breast cancer relapses. Virchows Arch 459: 31-39, 2011

37. Wu J, Hu D and Zhang R: Depletion of Bmi-1 enhances 5-fluorouracil-induced apoptosis and autophagy in hepatocellular carcinoma cells. Oncol Lett 4: 723-726, 2012

38. Wang E, Bhattacharyya S, Szabolcs A, et al: Enhancing chemotherapy response with Bmi-1 silencing in ovarian cancer. PLoS One 6: e17918, 2011.

39. Xin T, Zhang FB, Sui GJ and Jin XM: Bmi-1 siRNA inhibited ovarian cancer cell line growth and decreased telomerase activity. Br J Biomed Sci 69: 62-66, 2012.

40. Bhattacharyya J, Mihara K, Ohtsubo M, et al: Overexpression of BMI-1 correlates with drug resistance in B-cell lymphoma cells through the stabilization of survivin expression. Cancer Sci 103: 34-41, 2012.

41. Zhu Y, Yu F, Jiao Y, et al: Reduced miR-128 in breast tumor-initiating cells induces chemotherapeutic resistance via Bmi-1 and ABCC5. Clin Cancer Res 17: 7105-7115, 2011.

42. Liu ZG, Liu L, Xu LH, et al: Bmi-1 induces radioresistance in MCF-7 mammary carcinoma cells. Oncol Rep 27: 1116-1122, 2012.

43. Vrzalikova K, Skarda J, Ehrmann J, et al: Prognostic value of Bmi-1 oncoprotein expression in NSCLC patients: a tissue microarray study. J Cancer Res Clin Oncol 134: 1037-1042, 2008.

44. Balasubramanian S, Kanade S, Han B and Eckert RL: A proteasome inhibitor-stimulated Nrf1 protein-dependent compensatory increase in proteasome subunit gene expression reduces polycomb group protein level. J Biol Chem 287: 36179-36189, 2012.

45. Liu S, Tetzlaff MT, Cui R and Xu X: miR-200c inhibits melanoma progression and drug resistance through down-regulation of BMI-1. Am J Pathol 181: 1823-1835, 2012.

46. Qin ZK, Yang JA, Ye YL, et al: Expression of Bmi-1 is a prognostic marker in bladder cancer. BMC Cancer 9: 61, 2009.

47. Farivar S, Zati Keikha R, Shiari R and Jadali F: Expression of bmi-1 in pediatric brain tumors as a new independent prognostic marker of patient survival. Biomed Res Int 2013: 192548, 2013. 
48. Mimeault $\mathrm{M}$ and Batra SK: Frequent gene products and molecular pathways altered in prostate cancer- and metastasis-initiating cells and their progenies and novel promising multitargeted therapies. Mol Med 17: 949-964, 2011.

49. Park CH, Bergsagel DE and McCulloch EA: Mouse myeloma tumor stem cells: A primary cell culture assay. J Natl Cancer Inst 46: 411-422, 1971.

50. Oishi N and Wang XW: Novel therapeutic strategies for targeting liver cancer stem cells. Int J Biol Sci 7: 517-535, 2011.

51. Raaphorst FM: Self-renewal of hematopoietic and leukemic stem cells: a central role for the Polycomb-group gene Bmi-1. Trends Immunol 24: 522-524, 2003.

52. Iwama A, Oguro H, Negishi $M$, Kato $Y$ and Nakauchia $H$ : Epigenetic regulation of hematopoietic stem cell self-renewal by polycomb group genes. Int J Hematol 81: 294-300, 2005.

53. Gong H, Zhang YC and Liu WL: Regulatory effects of Bmi-1 gene on self-renewal of hematopoietic stem cells - review. Zhongguo Shi Yan Xue Ye Xue Za Zhi 14: 413-415, 2006 (In Chinese)

54. Park IK, Qian D, Kiel M, et al: Bmi-1 is required for maintenance of adult self-renewing haematopoietic stem cells. Nature 423 : 302-305, 2003

55. Lessard J and Sauvageau G: Bmi-1 determines the proliferative capacity of normal and leukaemic stem cells. Nature 423 : 255-260, 2003

56. Lee CJ, Dosch J and Simeone DM: Pancreatic cancer stem cells. J Clin Oncol 26: 2806-2812, 2008.

57. Molofsky AV, Pardal R, Iwashita T, Park IK, Clarke MF and Morrison SJ: Bmi-1 dependence distinguishes neural stem cell self-renewal from progenitor proliferation. Nature 425: 962-967, 2003.

58. Yu X, Jiang X, Li H, Guo L, Jiang W and Lu SH: miR-203 inhibits the proliferation and self-renewal of esophageal cancer stem-like cells by suppressing stem renewal factor Bmi-1. Stem Cells Dev 23: 576-585, 2014.

59. Ma J, Lanza DG, Guest I, et al: Characterization of mammary cancer stem cells in the MMTV-PyMT mouse model. Tumour Biol 33: 1983-1996, 2012.

60. Choy B, Bandla S, Xia Y, et al: Clinicopathologic characteristics of high expression of Bmi-1 in esophageal adenocarcinoma and squamous cell carcinoma. BMC Gastroenterol 12: 146, 2012.

61. Liu W, Feng JQ, Shen XM, Wang HY, Liu Y and Zhou ZT: Two stem cell markers, ATP-binding cassette, G2 subfamily (ABCG2) and BMI-1, predict the transformation of oral leukoplakia to cancer: a long-term follow-up study. Cancer 118: 1693-1700, 2012.

62. Gonzalez S, Klatt P, Delgado S, et al: Oncogenic activity of Cdc6 through repression of the INK4/ARF locus. Nature 440: 702-706, 2006.

63. Koh CM, Iwata T, Zheng Q, Bethel C, Yegnasubramanian S and De Marzo AM: Myc enforces overexpression of EZH2 in early prostatic neoplasia via transcriptional and post-transcriptional mechanisms. Oncotarget 2: 669-683, 2011.
64. Sander S, Bullinger L, Klapproth K, et al: MYC stimulates $\mathrm{EZH} 2$ expression by repression of its negative regulator miR-26a. Blood 112: 4202-4212,2008.

65. Ma L, Young J, Prabhala H, et al: miR-9, a MYC/MYCN-activated microRNA, regulates E-cadherin and cancer metastasis. Nat Cell Biol 12: 247-256, 2010.

66. Coskun V, Zhao J and Sun YE: Neurons or glia? Can SHP2 know it all? Sci STKE 2007: pe58, 2007.

67. Ke Y, Zhang EE, Hagihara K, et al: Deletion of Shp2 in the brain leads to defective proliferation and differentiation in neural stem cells and early postnatal lethality. Mol Cell Biol 27: 6706-6717, 2007.

68. Gao C, Kong NR and Chai L: The role of stem cell factor SALL4 in leukemogenesis. Crit Rev Oncog 16: 117-127, 2011.

69. Yang J, Chai L, Liu F, et al: Bmi-1 is a target gene for SALL4 in hematopoietic and leukemic cells. Proc Natl Acad Sci USA 104: 10494-10499, 2007.

70. Zhu J, Wang H, Sun Q, et al: Nrf2 is required to maintain the self-renewal of glioma stem cells. BMC Cancer 13: 380, 2013.

71. Won HY, Lee JY, Shin DH, et al: Loss of Mel-18 enhances breast cancer stem cell activity and tumorigenicity through activating Notch signaling mediated by the Wnt/TCF pathway. FASEB J 26: 5002-5013, 2012.

72. Jacobs JJ, Kieboom K, Marino S, DePinho RA and van Lohuizen M: The oncogene and Polycomb-group gene bmi-1 regulates cell proliferation and senescence through the ink4a locus. Nature 397: 164-168, 1999.

73. Lowe SW and Sherr CJ: Tumor suppression by Ink4a-Arf: progress and puzzles. Curr Opin Genet Dev 13: 77-83, 2003.

74. Carnero A, Hudson JD, Price CM and Beach DH: p16INK4A and p19ARF act in overlapping pathways in cellular immortalization. Nat Cell Biol 2: 148-155, 2000.

75. Chiba T, Seki A, Aoki R, et al: Bmil promotes hepatic stem cell expansion and tumorigenicity in both Ink4a/Arf-dependent and -independent manners in mice. Hepatology 52: 1111-1123, 2010.

76. Grinstein E and Wernet P: Cellular signaling in normal and cancerous stem cells. Cell Signal 19: 2428-2433, 2007.

77. Grinstein E and Mahotka C: Stem cell divisions controlled by the proto-oncogene BMI-1. J Stem Cells 4: 141-146, 2009.

78. Zacharek SJ, Fillmore CM, Lau AN, et al: Lung stem cell self-renewal relies on BMI1-dependent control of expression at imprinted loci. Cell Stem Cell 9: 272-281, 2011.

79. Bruggeman SW, Hulsman D and van Lohuizen M: Bmil deficient neural stem cells have increased integrin dependent adhesion to self-secreted matrix. Biochim Biophys Acta 1790: 351-360, 2009.

80. Fasano CA, Dimos JT, Ivanova NB, Lowry N, Lemischka IR and Temple S: shRNA knockdown of Bmi-1 reveals a critical role for p21-Rb pathway in NSC self-renewal during development. Cell Stem Cell 1: 87-99, 2007.

81. Jiang L, Song L, Wu J, et al: Bmi-1 promotes glioma angiogenesis by activating NF- $\mathrm{BB}$ signaling. PLoS One 8: e55527, 2013.

82. Vlachostergios PJ and Papandreou CN: The Bmi-1/NF- $\kappa B / V E G F$ story: another hint for proteasome involvement in glioma angiogenesis? J Cell Commun Signal 7: 235-237, 2013. 